\title{
Evaluating Trastuzumab and Lapatinib's Economic Impact in the Treatment of Metastatic Breast Cancer in Veneto Region Cohort
}

\author{
Simonetta Ballali ${ }^{1}$, Daniele Chiffi ${ }^{2}$, Marta P. Trojniak ${ }^{3}$, Dario Gregori ${ }^{*}, 2$ and the EIHCD-VeRo \\ Research Project Agreement ${ }^{\S}$
}

${ }^{I}$ Prochild Onlus, Trieste, Italy \& Unit of Biostatistics, Epidemiology and Public Health, Department of Cardiac, Thoracic and Vascular Sciences, University of Padova, Padova, Italy

${ }^{2}$ Unit of Biostatistics, Epidemiology and Public Health, Department of Cardiac, Thoracic and Vascular Sciences, University of Padova, Padova, Italy

${ }^{3}$ Oncology Pharmacy Department, Istituto Oncologico Veneto, IRCCS, Padova, Italy

\begin{abstract}
Objective: To assess the economic impact of the introduction of trastuzumab and lapatinib, as 1 st and 2 nd line treatment of HER-2 (Human Epidermal Growth Factor Receptor 2)-positive mBC (metastatic breast cancer) patients in Veneto region (North-East of Italy).

Methods: A Markov state decision model was implemented to evaluate the cost impact of trastuzumab and lapatinib use for a lapse of time of three years in Veneto public hospitals. The Markov model expressed transition probabilities from three different states, comparing in addition the expected deaths and the monthly survival rates in treatment and notreatment groups, along the lines of previously published studies.

Results: From the initial cohort of 267 patients eligible for treatment, stable ones (195) were considered in order to evaluate the impact of the targeted therapy on overall progression of the disease. Trastuzumab administration accounted for a regional expense of $2765662 €$ within the 6 months, almost duplicating in 1 year. $2^{\text {nd }}$ line therapy accounted on the 6 months budget for almost $100000 €$, costs overseen for the eligible patients at the beginning. All costs were considered together with the associated drug. Costs of second line treatment increased within the last year, taken the higher number of patients transiting from a stable condition to a progressive one.

Conclusion: Our result pointed out that $\mathrm{mBC}$ represents a considerably high cost also from a regional perspective. Economic evaluations are usually performed in different countries at national level, while in local health care decision making there is lack of health economic data and evaluations.
\end{abstract}

Keywords: Cost, HER-2+, lapatinib, metastastatic breast cancer, trastuzumab, Veneto.

*Address correspondence to this author at the Unit of Biostatistics, Epidemiology and Public Health, Department of Cardiac, Thoracic and Vascular Sciences, Via Loredan 18, 35121 Padova, Italy; Tel: +39 049 8275384; Fax: +39 02 700445089; E-mail: dario.gregori@unipd.it

${ }^{\S}$ EIHCD-VeRo (Economic Impact of High Cost Drugs in the Veneto Region) Research Project Agreement Members: Dario Gregori (Principal Investigator), Unit of Biostatistics, Epidemiology and Public Health, Department of Cardiac, Thoracic and Vascular Sciences, University of Padova, Padova, Italy; Daniele Chiffi, Unit of Biostatistics, Epidemiology and Public Health, Department of Cardiac, Thoracic and Vascular Sciences, University of Padova, Padova, Italy; Francesco Grigoletto, Department of Environmental Medicine and Public Health, University of Padova, Italy; Egle Perissinotto, Unit of Biostatistics, Epidemiology and Public Health, Department of Cardiac, Thoracic and Vascular Sciences, University of Padova, Padova, Italy; Alessandra Buja, Department of Molecular Medicine, University of Padova, Italy; Andrea Tramarina, Veneto Regional Health Agency, Italy; Costantino Gallo, Veneto Regional Health Agency, Italy; Antonio Compostella, Veneto Regional Health Agency, Italy; Davide Pastorelli, Istituto Oncologico del Veneto IRCSS, Padova, Italy; Giuseppe Rausa, Department of Environmental Medicine and Public Health, University of Padova, Italy.

\section{INTRODUCTION}

In 1975, the worldwide estimated number of new female cancers was 3 million. By 2000, this figure reached approximately 5 million [1]. Breast cancer is the most common malignancy in women [2]. As such, it accounts for more than $1 / 5$ of worldwide cancers prevalence. In the last ten years, an increase of $33 \%$ has been observed, accounting for $1,050,346$ new cases in the year 2000 [3]. The average 10 -year distant recurrence rate in early breast cancer is estimated at between 20 and $30 \%$ [4].

Incidence in the European Union is 109.8/100 000 women/ year, mortality sets around 38.4/100 000 women/year. Since 1990, the incidence rate has increased $1.5 \%$ annually [5]. Approximately $6 \%$ of breast cancers are metastatic at diagnosis with a 5 -year survival rate of $21 \%$.

Metastatic breast cancer $(\mathrm{mBC})$ remains essentially incurable, and the main treatment goal is palliation, with the aim of prolongation of overall survival time without 
negatively impacting quality of life. Due to advances both in early detection and in treatment options, mortality rates from breast cancer have been decreasing, however, it is still the leading cause of cancer mortality in women worldwide $(1,2)$. Currently, the treatment of patients with metastatic breast cancer $(\mathrm{mBC})$ involves the use of multiple agents, including endocrine therapies for hormone receptor-positive $(\mathrm{HR}+)$ disease, cytotoxic chemotherapy, and therapies targeting human epidermal growth factor (EGF) receptor 2 (HER-2) and vascular endothelial growth factor (VEGF) pathways. HER-2 has been recognized as acentral target for breast cancer [6]. HER-2 is amplified or overexpressed in approximately $20 \%$ of breast cancers, and increased HER-2 expression is linked with more aggressive breast tumors and before trastuzumab's introduction, with a prognosis less favorable than tumors with normal HER-2 expression [7].

Trastuzumab is a recombinant humanized monoclonal antibody that targets cancer cells that overexpress HER$2 /$ neu, a HER-2 oncogene. Among the estimated $20 \%$ to $30 \%$ of metastatic breast cancer patients whose tumors overexpress HER-2 [8], trastuzumab is recommended as first-line treatment, either as a single agent (in selected patients) or in combination with endocrine therapy or chemotherapy, as well as in the adjuvant setting, being associated not only with a significant improvement in mortality, but ending up in a drastic change of the natural history of the disease [9].

Dawood et al. recently reviewed the M. D. Anderson Cancer Center database and found that women with HER-2positive disease who received trastuzumab as first-line treatment had an improved prognosis compared to women with HER-2-negative disease [10]. Development of the tyrosine kinase inhibitor (TKI) lapatinib, which targets the inner part of the HER-2 receptor, has widened the therapeutic possibilities.

Lapatinib is a reversible dual EGFR/HER-1 and HER-2 TKI that is approved as $2^{\text {nd }}$ line agent, in combination with capecitabine for the treatment of advanced or HER-2+ breast cancer after failure of chemotherapy and trastuzumab. Lapatinib's linkage to the intracellular TK domains of HER1 and HER-2 results in inhibition of receptor phosphorylation, resulting in the inhibition of downstream pathways that control cell proliferation and survival. Lapatinib has shown a considerable increase in time to progression in combination with capecitabine in patients progressing after trastuzumab $[5,11]$.

The lifetime cost of $\mathrm{mBC}$ is a key component for the economic evaluations of these innovative products [12]: indeed the addition of targeted drugs for cancer treatment to standard chemotherapy entails a substantial growth of the costs related to cancer care determined by the high-costs of new anticancer drugs [13]. For example, the costeffectiveness of lapatinib in advanced breast cancer has been questioned. In a UK-NICE statement (2009), lapatinib in combination with capecitabine, within its licensed indication, is not recommended for the routine treatment of women with previously treated advanced or metastatic breast cancer whose tumors overexpress HER-2, except in the context of clinical trials [14].
In terms of public policy maker and its decision process, studies have shown that they resist applying rigorous health economic evaluations in the decision process, in particular since the available health-economic information is usually framed in a way which cannot be directly applied to a specific population [15]. The decision maker may deal in the economic evaluation studies with some methods like costeffectiveness ratio or quality-adjusted life years (QALY) gained, which poses some difficulties in being followed in the ordinary health-care domain because they rarely are providing data localized to the specific area or population [16]. The choice of well-specified points of view is an essential ingredient in the critical assessment of economic evaluation [17].

From the point of view of the health-care decision maker, the economic and clinical evaluation of a new therapy or health technology is more effective when information is presented in the general terms of a cost of illness analysis (COI), or, in a disaggregated way by means of a list of the costs and the outcomes or consequences of the intervention, namely as a cost consequence analysis (CCA) [18]. Furthermore, it has been observed that economic evaluations are usually performed in different countries at national level, while in local health care decision making there is lack of health economic data and evaluations, disconnecting economic evaluations from the types of decision that local institutions must normally face [19]. The NHS (National Health System) costs are controlled by the regional governments (which are financially accountable for health care expenditure, including hospital drug budgets), but agreements regarding price and discounts are decided in Agenzia italiana del farmaco (AIFA). For this reason, some regional governments ask the pharmaceutical companies to produce a "Health Technology Assessment" before deciding to introduce a drug in the regional hospital formulary.

Along the latter lines, the present paper is aimed at assessing the economic impact of the introduction of trastuzumab and lapatinib, in $1^{\text {st }}$ and $2^{\text {nd }}$ line treatment of HER-2-positive $\mathrm{mBC}$ patients in Veneto region (North-East of Italy). Whereas in previous work it has been calculated economic, health and social costs and consequences of the introduction of trastuzumab for the treatment of early stage breast cancer in Veneto region [20], in the current paper, a comparison concerning the introduction of targeted therapy as adjuvants in $\mathrm{mBC}$ treatment is also pointed out.

\section{MATERIALS AND METHODS}

\section{Target Therapy}

HER-2 was one of the first receptors targeted by specific monoclonal antibody trastuzumab [21]. Currently, it is used alone or as adjuvant with chemotherapy for treatment of breast cancer, especially in advanced stages of the disease. Trastuzumab is a recombinant humanized monoclonal antibody directed against the extracellular domain of HER-2 inhibiting receptor dimerization [21, 22]. The overall response rate to trastuzumab monotherapies is $\sim 26 \%$ compared to $40-60 \%$ when a trastuzumab-chemotherapy combination is applied [23]. Trastuzumab therapy has been accompanied with improved progression-free survival and consequently considered an indicative of host response to the antibody therapy [24]. Trastuzumab is normally 
administered in association with paclitaxel every 3 weeks with a loading dose of $8 \mathrm{mg} / \mathrm{kg}$ of body weight, followed by maintenance doses of $6 \mathrm{mg} / \mathrm{kg}$ of body weight or weekly with a loading dose of $4 \mathrm{mg} / \mathrm{kg}$ of body weight, followed by doses of $2 \mathrm{mg} / \mathrm{kg}$ of body weight. Lapatinib is a small-molecule potent reversible and selective inhibitor of the TK domains of EGFR and HER-2, that acts by competitive binding to the intracellular ATP-binding site of the receptor. It is registered for the treatment of advanced or metastatic HER-2+ breast cancer in combination with capecitabine and for hormone receptor-positive breast cancer in combination with an aromatase inhibitor [25]. Although monoclonal antibodies such as trastuzumab have resulted in significant clinical benefit for patients with HER-2-positive breast cancer [10], many patients exhibit intrinsic resistance and the common development of acquired resistance, remains a considerable clinical issue. Lapatinib cycle lasts 21 days and it consists of a daily oral dose of $1250 \mathrm{mg}$. It is given in association with capecitabine. All characteristics are presented in Table $\mathbf{1 .}$

\section{Setting}

Veneto is an Italian region with a population of 4.8 million. Veneto is situated in Northeast Italy and has a population of 4937854 (year 2010) among which the female population is 2523964 (year 2010) [26] and the incidence of new cases of breast cancer is about 4000 per year [27].

\section{Target Population}

The determination of the target population was obtained by taking into account the annual incidence of breast cancer patients, the criteria of clinical appropriateness, the yearly incidence rates of people with metastatic breast cancer at diagnosis, the proportion of patients presenting the HER-2 receptor and the proportion of patients which were not eligible to trastuzumab treatment because of heart dysfunction. All data were obtained from published studies $[9,28]$. Data on incidences and prevalences of $\mathrm{mBC}$ were obtained from the pharmacological database of IOV (Veneto Institute for Oncology) [27]. Target population of lapatinib's administration was calculated considering the yearly probabilities to be a first line refractory and being HER-2 (Table 4). All data were obtained from SISTAR website [26] and from major published studies $[9,13]$.

\section{Markov Model}

A Markov state decision model was implemented to evaluate the cost impact of trastuzumab and lapatinib use for a lapse of time of three years in Veneto public hospitals. The Markov model expressed transition probabilities from three different states (Fig. 1), comparing in addition the expected deaths and the monthly survival rates in treatment and notreatment groups, along the lines of previously published studies [28]. The transition probabilities for clinical variables are shown in Tables 2-4. Markov Model consists of 3 different states: "Stable disease", "Progressive disease", and "Dead". Patients start in the state "Stable disease" where they receive treatment. Patients could then respond to the therapy and remain in the "stable state" or move to a different state when the therapy failed "Progressive disease" or to the state "Dead". Patients in the "Progressive State" who were responding to the therapy, could remain in the same state, or instead switch to the "Death state". Death due to breast cancer is only possible for patients in the state "Progressive disease", otherwise the transition to "Dead" is

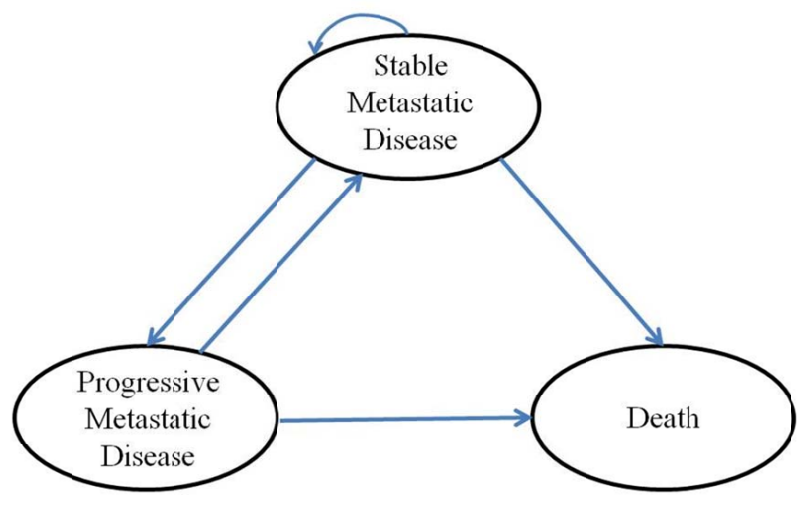

Fig. (1). Markov model.

Table 1. Characteristics of Anti-HER-2 Agents in Metastatic Breast Cancer (BW, Body Weight; BS, Body Surface)

\begin{tabular}{|c|c|c|}
\hline Trade name & Herceptin & Tyverb \\
\hline Administration & Infusion & Oral \\
\hline Line of treatment & 1 st & $\geq 2$ nd \\
\hline In combination with & $\begin{array}{l}\text { paclitaxel (in pts with no indication for anticyclin) or docetaxel or } \\
\text { Aromatase Inhibitors (in pts with ER/PR+) }\end{array}$ & capecitabine \\
\hline Frequency of single cycle & Every 3 weeks or Once a week & 21 days \\
\hline Dose Target Agent & $\begin{array}{l}\text { Loading dose: } 8 \mathrm{mg} / \mathrm{kg} \mathrm{BW} \mathrm{q} 3 \mathrm{w} ; 4 \mathrm{mg} / \mathrm{kg} \text { BW qw } \\
\text { Following doses: } 6 \mathrm{mg} / \mathrm{kg} \mathrm{q} 3 \mathrm{w} ; 2 \mathrm{mg} / \mathrm{kg} \text { BW qw }\end{array}$ & $1250 \mathrm{mg} / \mathrm{die}$ continuous \\
\hline
\end{tabular}


Table 2. Incidences and Probabilities of Transition Among Markov's Model Status in Patients Not Receiving Trastuzumab as $1^{\text {st }}$ Line Therapy

\begin{tabular}{|c|c|c|c|c|c|c|c|c|c|c|c|}
\hline$\underset{8}{8}$ & 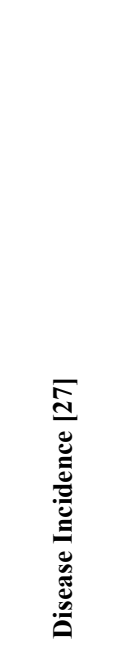 & 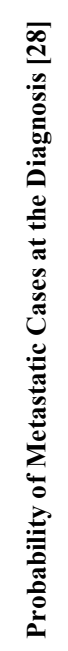 & 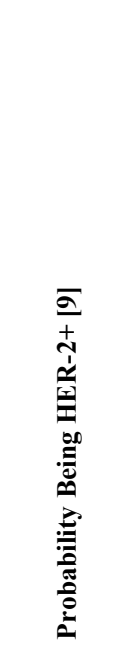 & 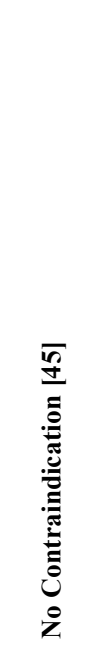 & 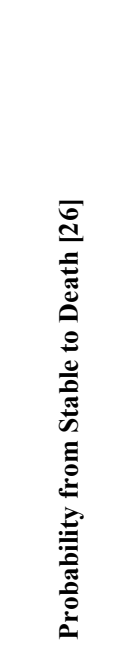 & 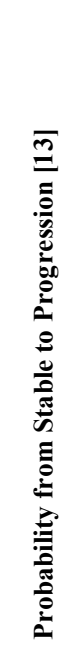 & 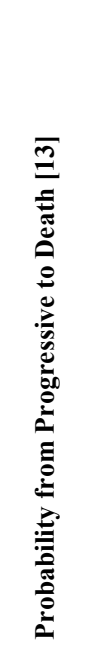 & 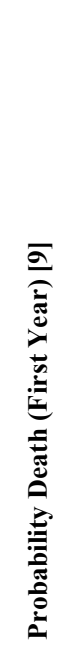 & 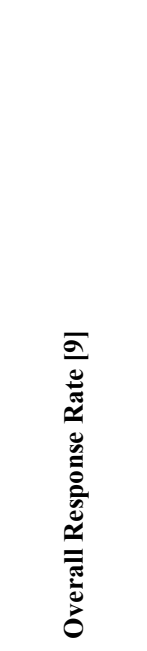 & 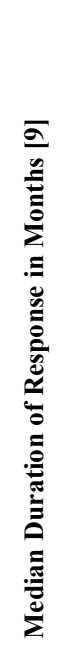 & 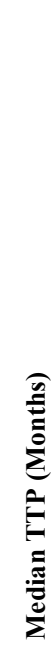 \\
\hline $0-24$ & 0.000004 & 0.06 & $0.25-0.30$ & 0.8206 & 0.0006761 & 0.107 & 0.095 & 0.33 & $0.26-0.38$ & 6.1 & 4.6 \\
\hline $25-49$ & 0.001 & 0.06 & $0.25-0.30$ & 0.8206 & 0.0008002 & 0.107 & 0.095 & 0.33 & $0.26-0.38$ & 6.1 & 4.6 \\
\hline $50-74$ & 0.0032 & 0.07 & $0.25-0.30$ & 0.769 & 0.0085 & 0.107 & 0.095 & 0.33 & $0.26-0.38$ & 6.1 & 4.6 \\
\hline$\geq 75$ & 0.0038 & 0.11 & $0.25-0.30$ & 0.745 & 0.011 & 0.107 & 0.095 & 0.33 & $0.26-0.38$ & 6.1 & 4.6 \\
\hline
\end{tabular}

Table 3. Incidences and Probabilities of Transition Among Markov's Model Status in Patients Receiving Trastuzumab as $1^{\text {st }}$ Line Therapy

\begin{tabular}{|c|c|c|c|c|c|c|c|c|c|c|c|}
\hline$\underset{8}{8}$ & 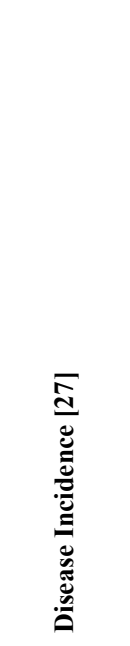 & 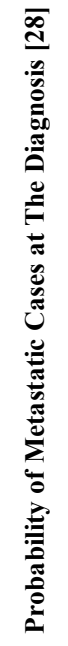 & 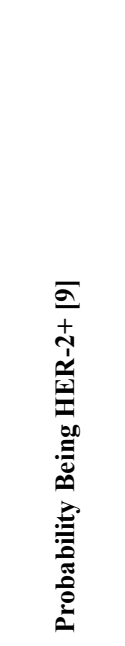 & 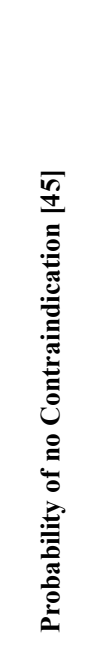 & 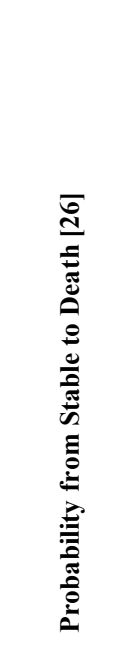 & 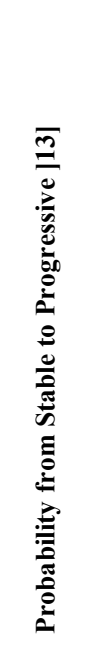 & 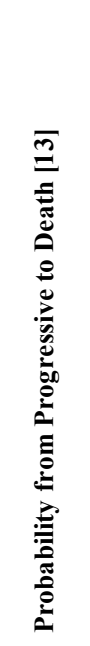 & 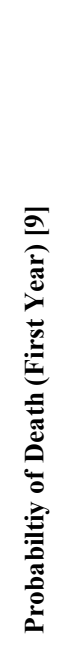 & 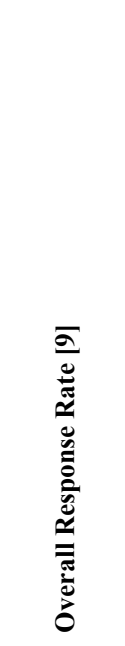 & 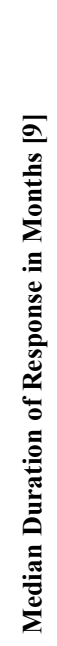 & 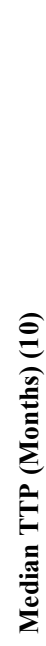 \\
\hline $0-24$ & 0.000004 & 0.06 & $0.25-0.30$ & 0.8206 & 0.0006761 & 0.058 & 0.047 & 0.22 & $0.44-0.57$ & 9.1 & 7.4 \\
\hline $25-49$ & 0.001 & 0.06 & $0.25-0.30$ & 0.8206 & 0.0008002 & 0.058 & 0.047 & 0.22 & $0.44-0.57$ & 9.1 & 7.4 \\
\hline $50-74$ & 0.0032 & 0.07 & $0.25-0.30$ & 0.769 & 0.0085 & 0.058 & 0.047 & 0.22 & $0.44-0.57$ & 9.1 & 7.4 \\
\hline$\geq 75$ & 0.0038 & 0.11 & $0.25-0.30$ & 0.745 & 0.011 & 0.058 & 0.047 & 0.22 & $0.44-0.57$ & 9.1 & 7.4 \\
\hline
\end{tabular}

due to other causes. The reference population mimics the distribution of the Veneto population, assuming a median drug dosage for a person of $60 \mathrm{kgs}$.

The Markov model structure followed a conventional design in which patients were followed from first-line treatment until death, in a 6 months period. Patients were assumed to receive active treatment until an investigator's assessment of tumor progression was confirmed. Transition probabilities (reflecting the 6-month cycle length) for trastuzumab and for lapatinib were derived from major published studies $[9,13,29]$, necessary for the drug approval of Food and Drug Administration (FDA) and European 
Table 4. Incidences and Probabilities of Transition Among Markov's Model Status in Patients Receiving Lapatinib as $2^{\text {nd }}$ Line Therapy

\begin{tabular}{|c|c|c|c|c|c|c|c|c|c|c|c|c|c|}
\hline$\stackrel{8}{\gtrless}$ & 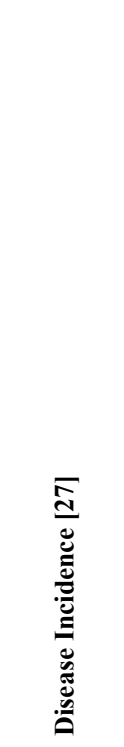 & 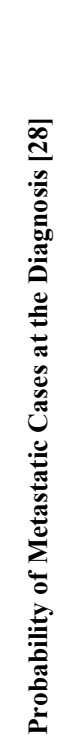 & 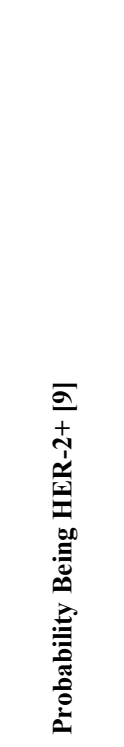 & 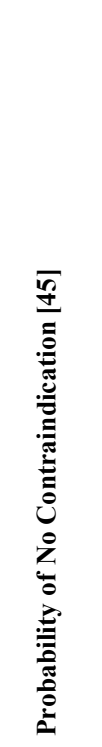 & 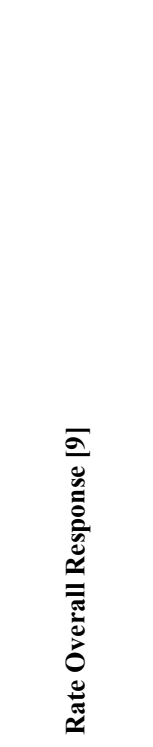 & 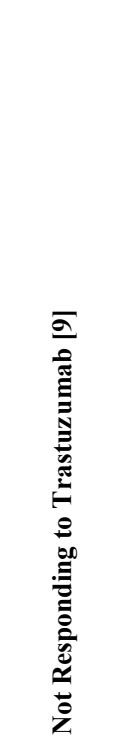 & 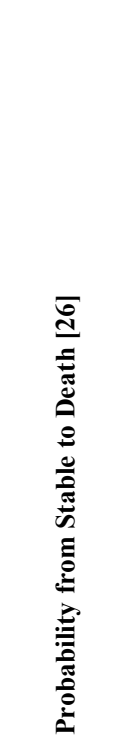 & 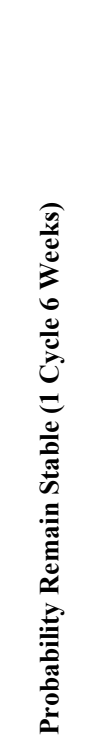 & 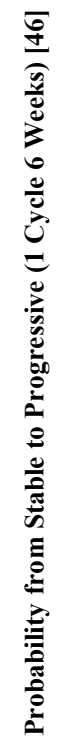 & 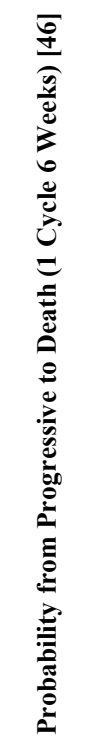 & 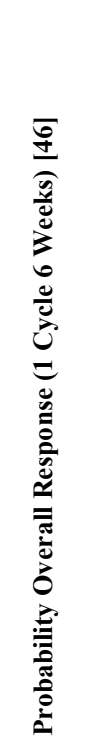 & 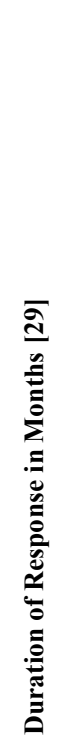 & 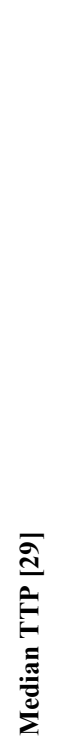 \\
\hline $0-24$ & 0.000004 & 0.06 & $0.25-0.30$ & 0.8206 & $0.44-0.57 \%$ & $0.43-0.56$ & 0.0006761 & 0.7440 & 0.14 & 0.0540 & 0.620 & 8.4 & 8.4 \\
\hline $25-9$ & 0.001 & 0.06 & $0.25-0.30$ & 0.8206 & $0.44-0.57 \%$ & $0.43-0.56$ & 0.0008002 & 0.7440 & 0.14 & 0.0540 & 0.620 & 8.4 & 8.4 \\
\hline $50-4$ & 0.0032 & 0.07 & $0.25-0.30$ & 0.769 & $0.44-0.57 \%$ & $0.43-0.56$ & 0.0085 & 0.7440 & 0.14 & 0.0540 & 0.620 & 8.4 & 8.4 \\
\hline$\geq 75$ & 0.0038 & 0.11 & $0.25-030$ & 0.745 & $0.44-0.57 \%$ & $0.43-0.56$ & 0.011 & 0.7440 & 0.14 & 0.0540 & 0.620 & 8.4 & 8.4 \\
\hline
\end{tabular}

Medicines Agency (EMA), and institutional-derived data from IOV [27]. Monthly transition probabilities were determined from first year clinical probabilities, using the following formula:

$P=1-e^{-r t}$

where, $P$ is the probability of the event, e the natural logarithm, $r$ the rate, and $t$ being the time interval [17]. A time period of three years was considered adequate to assess the economic impact. The costs were related to the cost of drug for a full cycle treatment of 6 months. Three scenarios were simulated in order to determine the impact on $\mathrm{mBC}$ population. The first one where patients were receiving trastuzumab together with paclitaxel as $1^{\text {st }}$ line treatment, while in the second one, they were receiving only paclitaxel. The third model considered patients treated with lapatinib together with capecitabine as $2^{\text {nd }}$ line agent, after receiving a $1^{\text {st }}$ line treatment of trastuzumab plus paclitaxel.

\section{Simulations}

A micro-simulation approach has been used as the main setting for the analysis. All quantities described above have been implemented in the stochastic simulation model as expected values of suitable probability functions. In more detail, for discrete random variables (e.g.: number of people incident for breast cancer), a binomial model has been used (e.g.: sampling from the Veneto population with probability equal to the age-specific incidence rate). For continuous random variables (e.g.: weight of patients for drug dosage administration), including costs, a Kumaraswamy distribution, which is very flexible both as symmetric and asymmetric two-parameters distribution, has been used [30]. Thus, 10000 Monte Carlo runs have been performed, deriving the empirical distributions of the target quantities of interest (e.g.: cost of care), for which selected summary measures have been computed (e.g.: mean, $5^{\text {th }}$ and $95^{\text {th }}$ percentile, to be used as $90 \%$ credibility intervals for inferential purposes). All estimated quantities are reported along with $90 \%$ credibility intervals. Software used for simulations was the VOSE Model Risk analyzer [31].

\section{RESULTS}

The impact of trastuzumab and lapatinib was evaluated considering $1^{\text {st }}$ and $2^{\text {nd }}$ line treatment, respectively, in $\mathrm{mBC}$ patients for a full period of 3 years in Veneto region. Patients eligible for trastuzumab therapy were those in a stable condition with a HER-2+ breast cancer. When comparing the impact of trastuzumab on patients, results showed similar results both in progression and number of deaths. As shown in Table 5, despite the highest aggressiveness of HER-2+ $\mathrm{mBC}$, trastuzumab patients maintained the same trends of response of patients receiving the usual chemotherapy treatment. The impact of lapatinib was evaluated in patients eligible to receive $2^{\text {nd }}$ line therapy, after a $1^{\text {st }}$ line treatment of trastuzumab.

From the initial cohort of 267 patients eligible for treatment, stable ones (195) were considered in order to evaluate the impact of the targeted agents on overall progression of the disease. When considering trastuzumab impact, progression within the first 6 months was seen in the $31 \%$ of patients, while the rates of death transitions were 
Table 5. Impact of Regular Therapy and Targeted Drugs Use on Overall Survival and Progression of mBC Patients of Veneto's Cohort. All Data are Presented with a 90\% C.I.

\begin{tabular}{|l|c|c|c|}
\hline & $\begin{array}{c}\text { Pts receiving Trastuzumab as } \\
\text { 1st Line Treatment }\end{array}$ & $\begin{array}{c}\text { Pts Not Receiving Trastuzumab } \\
\text { as 1st Line Treatment }\end{array}$ & $\begin{array}{c}\text { Pts Receiving Lapatinib as } \\
\text { 2nd Line Treatment }\end{array}$ \\
\hline \hline Eligible at the beginning & $267(239 ; 300)$ & $269(239 ; 299)$ & Not applicable \\
\hline Stable at the beginning & $195(168 ; 223)$ & $227(200 ; 257)$ & Not applicable \\
\hline Eligible in 36 months & Not applicable & Not applicable & $69(41 ; 78)$ \\
\hline in Progression by the 6th month & $60(46 ; 75)$ & $30(21 ; 40)$ & $15(9 ; 22)$ \\
\hline in Progression by the 12th month & $54(41 ; 68)$ & $28(19 ; 37)$ & $13(7 ; 20)$ \\
\hline in Progression by the 18th month & $43(32 ; 55)$ & $23(16 ; 32)$ & $9(4 ; 14)$ \\
\hline in Progression by the 24th month & $27(18 ; 36)$ & $16(10 ; 23)$ & $3(1 ; 16)$ \\
\hline in Progression by the 30th month & $11(5 ; 16)$ & $8(4 ; 13)$ & $0(0 ; 2)$ \\
\hline in Progression by the 36th month & $2(0 ; 4)$ & $2(0 ; 4)$ & $1(0 ; 2)$ \\
\hline Dead by the 6th month & $14(8 ; 20)$ & $11(6 ; 16)$ & $3(0 ; 6)$ \\
\hline Dead by the 12th month & $41(31 ; 53)$ & $33(23 ; 43)$ & $10(5 ; 16)$ \\
\hline Dead by the 18th month & $89(72 ; 107)$ & $72(57 ; 87)$ & $24(16 ; 33)$ \\
\hline Dead by the 24th month & $156(132 ; 181)$ & $131(110 ; 154)$ & $38(27 ; 50)$ \\
\hline Dead by the 30th month & $224(194 ; 256)$ & $202(174 ; 230)$ & $43(31 ; 56)$ \\
\hline Dead by the 36th month & $262(229 ; 296))$ & $253(222 ; 285)$ & \\
\hline
\end{tabular}

achieved $98 \%$ within the first 3 years. Lapatinib use was associated with a survival rate of $27 \%$ in a period of 3 years.

Costs of treatment are presented in Table 6. Trastuzumab administration accounted for a regional expense of 2765662 $€$ within the 6 months, almost duplicating in 1 year (Table 6). $2^{\text {nd }}$ line therapy accounted on the 6 months budget for almost $100000 €$, costs overseen for the eligible patients at the beginning. All costs were considered together with the associated drug, as explicated in Table 1. Costs of second line treatment increased within the last year, taken the higher number of patients transiting from a stable condition to a progressive one.

\section{DISCUSSION}

Breast is the most common site of cancer in women worldwide, accounting for approximately $25 \%$ of female cancers, with higher rates in North America, Western and Northern Europe, and Australia [32].
The prevalence of breast cancer is increasing taken progresses on the overall survival of the patients. Outcomes have improved as a result of progress in all major aspects of multidisciplinary care. These include surgery, radiotherapy, hormonal therapy, chemotherapy and newer targeted drugs. Decisions regarding the timing and aggressiveness of therapy are influenced by the site of the metastases. Objective responses to some chemotherapy regimens are common, but few patients with metastasis are cured [33] and treatment might imply substantial adverse effects [32]. $\mathrm{mBC}$, either found at initial presentation, or after treatment, occurs in $40 \%$ of breast cancer patients [4]. Women with breast cancers that overexpress HER-2 have an aggressive form of the disease with significantly shortened disease-free survival and overall survival [34]. The advent of targeted therapies, anti-HER-2 and antiangiogenic therapies, gives more strategic options in $\mathrm{mBC}$ management. These agents are not necessarily less toxic than traditional cytotoxics since potentially they are associated with serious adverse events. Actual research focuses on the development of biologic

Table 6. Cost Impact of Anti-HER-2 Drugs in Association with Chemotherapy in $\mathrm{mBC} 1^{\text {st }}$ and $2^{\text {nd }}$ Line Treatments. Lapatinib Costs has been Considered as Cumulative with Previous 1st Line Treatments. All Costs are Given with a $90 \%$ C.I.

\begin{tabular}{|c|c|c|}
\hline Cumulative Cost (€) & Trastuzumab + Paclitaxel & $\begin{array}{c}\text { Trastuzumab + Paclitaxel ( }\left(1^{\text {st }} \text { Line }\right) \\
\text { Lapatimib + Capecitabine }\left(2^{\text {nd }} \text { Line }\right)\end{array}$ \\
\hline at 6th month & $2765662(1952414 ; 3624763)$ & $2860417(2041610 ; 3728422)$ \\
\hline at 12 th month & $5218245(3678492 ; 6832740)$ & $5422154(3870426 ; 7056847)$ \\
\hline at 18th month & $7161248(5031852 ; 9408276)$ & $7534876(5388511 ; 9798758)$ \\
\hline at 24th month & $8380218(5890977 ; 11031288)$ & $8876159(6350390 ; 11541820)$ \\
\hline at 30th month & $8860272(6212200 ; 11663988)$ & $9391502(6714179 ; 12223660)$ \\
\hline at 36th month & $8934821(6262200 ; 11759706)$ & $9468121(6761737 ; 12333059)$ \\
\hline
\end{tabular}


markers of disease; consequently targeted strategies will continue to become more individualized.

Trastuzumab-based combination therapy has shown effectiveness in reducing the relative risk death by $20 \%$ at a median follow-up of 30 months [9]. Literature reports the incremental cost-utility ratio for Trastuzumab as between 14.861 Euros per quality adjusted life year gained [35] and 25.990 euros per quality adjusted life year gained [36], but this information alone is not sufficient to allow policy makers to establish the true incremental costs for implementation of this strategy at the local level. Trastuzumab use and cost effectiveness have been broadly debated. Several studies highlighted the cost effectiveness of this therapy [35, 37], while others results were stressing the doubtfulness of it, mostly relaying on the evaluation of clinical results [38]. Same considerations can be made for lapatinib use and diffusion. Lapatinib was recently developed, and survival data will be essential to justify its costs to the public administrators [25]. The activity of lapatinib in refractory $\mathrm{mBC}$, with potential benefit in patients with brain metastases, has generated general interest, becoming increasingly used in $2^{\text {nd }}$ and $3^{\text {rd }}$ lines treatment. Interim results from a large, phase III trial in 392 patients showed that in combination with capecitabine, lapatinib almost doubled time to progression when compared with capecitabine alone [39].

The use of targeted therapies in real world patients still bears several uncertainties. There are important and unanswered questions about the use of targeted therapies in the real world, as pointed out by Philipps [40]. Selection of patients eligible for treatment, accurateness of HER-2 testing in the clinical setting, testing and treatment approaches used to direct targeted HER-2 therapy in actual clinical practice, are those essential steps which cannot be solved with hypothetical cohort simulations gathered mainly by data from trials or early-stage applications. Although real-world effectiveness estimates are often unavailable or difficult to generate, several other steps can be taken, including the incorporation of local use patterns to improve figures and behavioral assumptions.

Our results pointed out that $\mathrm{mBC}$ represents a considerably high cost for the NHS. Having this in mind, when implementing a program, it is important to identify patients with characteristics that place them at risk of incurring more utilization and higher health care costs. Our findings suggest that patients with HER-2+ $\mathrm{mBC}$ will benefit from trastuzumab therapeutic treatment as $1^{\text {st }}$ line, switching to lapatinib as $2^{\text {nd }}$ line treatment in case of failure of the first one. In order to achieve this and taken the impact on patients, a shorter period of treatment should be considered, as in the first 12 months patients seemed to obtain the highest benefits. The per-patient cost of advanced breast cancer is high, and hospital services are the largest components of these costs [41].

Besides considering the impact of treatment on regional health budget, breast cancer screening costs should be considered when evaluating the impact of $\mathrm{mBC}$ treatments. Early detection and treatment can prevent the development of breast cancer in $75 \%$ of cases and reduce $30 \%$ of breast cancer mortality [42]. The WHO recommends all women between the ages of 50 and 69 to have breast screening every two years [42]. A recent Italian study considering the costs of breast cancer screening within an organized national framework [43] estimated a median value of 55,5 $€$ per screened women. Breast cancer screening would probably represent a costly investment for the Italian healthcare system if adopted on a large scale, but it could avoid subsequent high costs for advanced stages treatment. The Italian NHS established in 1978 follows a model similar to the Beveridge model developed by the British National Health System [44]. Healthcare coverage is provided by the government through taxes, uniformly giving access to the healthcare system to the whole Italian population. However, power has progressively been shifted from the state to the regions, due to the decentralization process occurred since the early $90 \mathrm{~s}$. This lead to a reduced power held from the state, that kept in any case its role of in order to ensure uniform and essential levels of health services across the country. The state allocates financial resources to the 20 regions, assigning legislative jurisdiction over health care decisions. Thus, it is essential to provide to the regional decision makers specific information about the single regions, in particular on cost-effectiveness of interventions, in order to distribute efficiently health-related financial resources.

\section{CONFLICT OF INTEREST}

The authors certify that there is no conflict of interest with any organization regarding the material discussed in the manuscript.

\section{ACKNOWLEDGEMENTS}

This research was partially funded by an unrestricted grant of the University of Padova, Progetti di Ateneo 2009, (Code CPDA093183/09, "Modello per la valutazione dell'impatto economico, sociale e di salute derivante dall'utilizzo dei nuovi farmaci oncologici nella regione Veneto").

\section{REFERENCES}

[1] Pecorelli, S.; Favalli, G.; Zigliani, L.; Odicino, F. Cancer in women. Int. J. Gynaecol. Obstet., 2003, 82 (3), 369-379.

[2] Boyle, P. Global burden of cancer. Lancet, 1997, 349 Suppl 2, SII23- SII26.

[3] (a) Jones, S. B. Cancer in the developing world: a call to action. $B M J$, 1999, 319 (7208), 505-508; (b) Parkin, D. M. Global cancer statistics in the year 2000. Lancet Oncol., 2001, 2 (9), 533-543.

[4] EBCTCG. Effects of chemotherapy and hormonal therapy for early breast cancer on recurrence and 15-year survival: an overview of the randomised trials. Lancet, 2005, 365 (9472), 1687-1717.

[5] Cardoso, F.; Castiglione, M. Locally recurrent or metastatic breast cancer: ESMO clinical recommendations for diagnosis, treatment and follow-up. Ann. Oncol., 2009, 20 Suppl 4, 15-18.

[6] Slamon, D. J.; Clark, G. M.; Wong, S. G.; Levin, W. J.; Ullrich, A.; McGuire, W. L. Human breast cancer: correlation of relapse and survival with amplification of the HER-2/neu oncogene. Science, 1987, 235 (4785), 177-182.

[7] Awada, A.; Bozovic-Spasojevic, I.; Chow, L. New therapies in HER2-positive breast cancer: a major step towards a cure of the disease? Cancer Treat. Rev. 2012, 38 (5), 494-504.

[8] Slamon, D. J.; Godolphin, W.; Jones, L. A.; Holt, J. A.; Wong, S. G.; Keith, D. E.; Levin, W. J.; Stuart, S. G.; Udove, J.; Ullrich, A.; Press, M. F. Studies of the HER-2/neu proto-oncogene in human breast and ovarian cancer. Science, 1989, 244 (4905), 707-712.

[9] Slamon, D. J.; Leyland-Jones, B.; Shak, S.; Fuchs, H.; Paton, V.; Bajamonde, A.; Fleming, T.; Eiermann, W.; Wolter, J.; Pegram, M.; Baselga, J.; Norton, L. Use of chemotherapy plus a monoclonal 
antibody against HER2 for metastatic breast cancer that overexpresses HER2. N. Engl. J. Med., 2001, 344 (11), 783-792.

[10] Dawood, S.; Broglio, K.; Buzdar, A. U.; Hortobagyi, G. N.; Giordano, S. H. Prognosis of women with metastatic breast cancer by HER2 status and trastuzumab treatment: an institutional-based review. J. Clin. Oncol., 2010, 28 (1), 92-98.

[11] Crivellari, D.; Spazzapan, S.; Lombardi, D.; Militello, L.; Torrisi, E.; Russo, A. E.; Sorio, R.; Talamini, R.; Miolo, G.; Carli, P.; Veronesi, A. Lapatinib-based therapy in heavily pretreated HER2positive metastatic breast cancer: a single institution experience. Tumori, 2012, 98 (1), 33-38.

[12] Bonastre, J.; Jan, P.; Barthe, Y.; Koscielny, S. Metastatic breast cancer: We do need primary cost data. Breast, 2012, 21 (3), 384388.

[13] Lidgren, M.; Wilking, N.; Jönsson, B. Cost of breast cancer in Sweden in 2002. Health Econ., 2007, 8 (1), 5-15.

[14] Cheema, P. K.; Gavura, S.; Migus, M.; Godman, B.; Yeung, L.; Trudeau, M. E. International variability in the reimbursement of cancer drugs by publically funded drug programs. Curr. Oncol., 2012, 19 (3), e165-e176.

[15] Smith, N.; Mitton, C.; Peacock, S. Qualitative methodologies in health-care priority setting research. Health Econ., 2009, 18 (10), 1163-1175.

[16] Christiane, H. The influence of economic evaluation studies on decision making.: A European survey. Health Policy, 2000, 52 (3), 179-192.

[17] Drummond, M. F.; Sculpher, M. J.; Torrance, W. G.; O'Brien, B. J.; Stoddart, G. L. Methods for the Economic Evaluation of Health Care Programmes. $3^{\text {rd }}$ ed.; Oxford University Press: Oxford ; New York, 2005, p. 379.

[18] Mauskopf, J. A.; Paul, E. J.; Grant., M. D.; Stergachis, A. the role of cost-consequence analysis in healthcare decision-making. Pharmacoeconomics, 1998, 13, 277-288.

[19] Oya, E.; Joanna, C. Use of economic evaluation in local health care decision-making in England: A qualitative investigation. Health Policy, 2009, 89 (3), 261-270.

[20] Buja, A.; Perissinotto, E.; Compostella, A.; Tramarin, A.; Rebba, V.; Pastorelli, D.; Grigoletto, F.; Gallo, C.; Rausa, G.; Gregori, D. Taking decisions on expenditure for high-cost drugs at the regional level: a model for evaluating the overall impact of Trastuzumab in the Veneto Region of Italy. J. Eval. Clin. Pract., 2011, 17 (2), 298303

[21] Carter, P.; Presta, L.; Gorman, C. M.; Ridgway, J. B.; Henner, D.; Wong, W. L.; Rowland, A. M.; Kotts, C.; Carver, M. E.; Shepard, H. M. Humanization of an anti-p185HER2 antibody for human cancer therapy. Proc. Natl. Acad. Sci. USA, 1992, 89 (10), 42854289.

[22] Ghosh, R.; Narasanna, A.; Wang, S. E.; Liu, S.; Chakrabarty, A.; Balko, J. M.; Gonzalez-Angulo, A. M.; Mills, G. B.; Penuel, E.; Winslow, J.; Sperinde, J.; Dua, R.; Pidaparthi, S.; Mukherjee, A.; Leitzel, K.; Kostler, W. J.; Lipton, A.; Bates, M.; Arteaga, C. L. Trastuzumab has preferential activity against breast cancers driven by HER2 homodimers. Cancer. Res., 2011, 71 (5), 1871-1882.

[23] (a) Vogel, C. L.; Cobleigh, M. A.; Tripathy, D.; Gutheil, J. C.; Harris, L. N.; Fehrenbacher, L.; Slamon, D. J.; Murphy, M.; Novotny, W. F.; Burchmore, M.; Shak, S.; Stewart, S. J.; Press, M. Efficacy and safety of trastuzumab as a single agent in first-line treatment of HER2-overexpressing metastatic breast cancer. $J$. Clin. Oncol., 2002, 20 (3), 719-726; (b) Seidman, A. D.; Berry, D.; Cirrincione, C.; Harris, L.; Muss, H.; Marcom, P. K.; Gipson, G.; Burstein, H.; Lake, D.; Shapiro, C. L.; Ungaro, P.; Norton, L.; Winer, E.; Hudis, C. Randomized phase III trial of weekly compared with every-3-weeks paclitaxel for metastatic breast cancer, with trastuzumab for all HER-2 overexpressors and random assignment to trastuzumab or not in HER-2 nonoverexpressors: final results of Cancer and Leukemia Group B protocol 9840. J. Clin. Oncol., 2008, 26 (10), 1642-1649.

[24] Fornier, M. N.; Seidman, A. D.; Schwartz, M. K.; Ghani, F.; Thiel, R.; Norton, L.; Hudis, C. Serum HER2 extracellular domain in metastatic breast cancer patients treated with weekly trastuzumab and paclitaxel: association with HER2 status by immunohistochemistry and fluorescence in situ hybridization and with response rate. Ann. Oncol., 2005, 16 (2), 234-9.

[25] Kopper, L. Lapatinib: a sword with two edges. Pathol. Oncol. Res., 2008, 14 (1), 1-8.
SISTAR. Available at: http://statistica.regione.veneto.it/sistar/inde $\mathrm{x} . \mathrm{jsp}$

[27] Available at: IOV http://www.registrotumoriveneto.it/home.asp

[28] (a) Lidgren, M.; Wilking, N.; Jonsson, B.; Rehnberg, C. Costeffectiveness of HER2 testing and trastuzumab therapy for metastatic breast cancer. Acta. Oncol., 2008, 47 (6), 1018-10128; (b) Romond, E. H.; Perez, E. A.; Bryant, J.; Suman, V. J.; Geyer, C. E., Jr.; Davidson, N. E.; Tan-Chiu, E.; Martino, S.; Paik, S.; Kaufman, P. A.; Swain, S. M.; Pisansky, T. M.; Fehrenbacher, L.; Kutteh, L. A.; Vogel, V. G.; Visscher, D. W.; Yothers, G.; Jenkins, R. B.; Brown, A. M.; Dakhil, S. R.; Mamounas, E. P.; Lingle, W. L.; Klein, P. M.; Ingle, J. N.; Wolmark, N. Trastuzumab plus adjuvant chemotherapy for operable HER2-positive breast cancer. N. Engl. J. Med., 2005, 353 (16), 1673-1684.

[29] Geyer, C. E.; Forster, J.; Lindquist, D.; Chan, S.; Romieu, C. G.; Pienkowski, T.; Jagiello-Gruszfeld, A.; Crown, J.; Chan, A.; Kaufman, B.; Skarlos, D.; Campone, M.; Davidson, N.; Berger, M.; Oliva, C.; Rubin, S. D.; Stein, S.; Cameron, D. Lapatinib plus capecitabine for HER2-positive advanced breast cancer. $N$. Engl. J. Med., 2006, 355 (26), 2733-2743.

[30] Kumaraswamy, P. A generalized probability density function for double-bounded random processes. J. Hydr., 1980, 46 (1-2), 79-88.

[31] Van Hauwermeiren, M.; Vose, D.; Vanden Bossche, S. A Compendium of Distributions. Software, V., Ed. Ghent, Belgium, 2012. Available at: www.vosesoftware.com [Accessed: 29 May 2012].

[32] Althuis, M. D.; Dozier, J. M.; Anderson, W. F.; Devesa, S. S.; Brinton, L. A. Global trends in breast cancer incidence and mortality 1973-1997. Int. J. Epidemiol., 2005, 34 (2), 405-412.

[33] Greenberg, P. A.; Hortobagyi, G. N.; Smith, T. L.; Ziegler, L. D.; Frye, D. K.; Buzdar, A. U. Long-term follow-up of patients with complete remission following combination chemotherapy for metastatic breast cancer. J. Clin. Oncol., 1996, 14 (8), 2197-2205.

[34] Seshadri, R.; Firgaira, F. A.; Horsfall, D. J.; McCaul, K.; Setlur, V.; Kitchen, P. Clinical significance of HER-2/neu oncogene amplification in primary breast cancer. The South Australian Breast Cancer Study Group. J. Clin. Oncol., 1993, 11 (10), 1936-1942.

[35] Liberato, N. L.; Marchetti, M.; Barosi, G. Cost effectiveness of adjuvant trastuzumab in human epidermal growth factor receptor 2positive breast cancer. J. Clin. Oncol., 2007, 25 (6), 625-633.

[36] Dahabreh, I. J.; Linardou, H.; Siannis, F.; Fountzilas, G.; Murray, S. Trastuzumab in the adjuvant treatment of early-stage breast cancer: a systematic review and meta-analysis of randomized controlled trials. Oncologist, 2008, 13 (6), 620-630.

[37] (a) Millar, J. A.; Millward, M. J. Cost effectiveness of trastuzumab in the adjuvant treatment of early breast cancer: a lifetime model. Pharmacoeconomics, 2007, 25 (5), 429-442; (b) Garrison, L. P., Jr.; Lubeck, D.; Lalla, D.; Paton, V.; Dueck, A.; Perez, E. A. Costeffectiveness analysis of trastuzumab in the adjuvant setting for treatment of HER2-positive breast cancer. Cancer, 2007, 110 (3), 489-498.

[38] (a) Hall, P. S.; Hulme, C.; McCabe, C.; Oluboyede, Y.; Round, J.; Cameron, D. A. Updated cost-effectiveness analysis of trastuzumab for early breast cancer: a UK perspective considering duration of benefit, long-term toxicity and pattern of recurrence. Pharmacoeconomics, 2011, 29 (5), 415-432; (b) Wu, B.; Ye, M.; Chen, H.; Shen, J. F. Costs of trastuzumab in combination with chemotherapy for HER2-positive advanced gastric or gastroesophageal junction cancer: an economic evaluation in the Chinese context. Clin. Ther., 2012, 34 (2), 468-479.

[39] Bilancia, D.; Rosati, G.; Dinota, A.; Germano, D.; Romano, R.; Manzione, L. Lapatinib in breast cancer. Ann. Oncol., 2007, 18 Suppl 6, vi26- vi30.

[40] Phillips, K. A.; Liang, S. Y.; Van Bebber, S. Challenges to the translation of genomic information into clinical practice and health policy: Utilization, preferences and economic value. Curr. Opin. Mol. Ther., 2008, 10 (3), 260-266.

[41] Davis, K. L.; Mitra, D.; Kotapati, S.; Ibrahim, R.; Wolchok, J. D. Direct economic burden of high-risk and metastatic melanoma in the elderly: evidence from the SEER-Medicare linked database. Appl. Health Econ. Health Policy, 2009, 7 (1), 31-41.

[42] WHO. Preventing chronic diseases: a vital investment. WHO Global Report. WHO: Geneva, 2005.

[43] ISPO; IOV; USL8Arezzo Analisi dei costi nei programmi di screening organizzato $e$ in setting opportunistici nell'ambito della prevenzione per il tumore della mammella; Roma, 2011. 
[44] (a) Anonymous. The Beveridge Plan. Br. Med. J., 1942, 2 (4275), 700; (b) Musgrove, P. Health insurance: the influence of the Beveridge Report. Bull. World Health Organ., 2000, 78 (6), 845846.
[45] Neyt, M.; Huybrechts, M.; Hulstaert, F.; Vrijens, F.; Ramaekers, D. Trastuzumab in early stage breast cancer: A cost-effectiveness analysis for Belgium. Health Policy, 2008, 87 (2), 146-159.

[46] Le, Q. A.; Hay, J. W. Cost-effectiveness analysis of lapatinib in HER-2-positive advanced breast cancer. Cancer, 2009, 115 (3), $489-498$

Received: October 9, 2012

(C) Ballali et al.; Licensee Bentham Open.

This is an open access article licensed under the terms of the Creative Commons Attribution Non-Commercial License (http://creativecommons.org/licenses/by$\mathrm{nc} / 3.0 /$ ) which permits unrestricted, non-commercial use, distribution and reproduction in any medium, provided the work is properly cited. 